\title{
Prospective study of malabsorption induced risk of gall stone formation in relation to fall in plasma cholesterol
}

\author{
T I A SØRENSEN, B ANDERSEN, E HYLANDER, L I JENSEN, \\ K LAURSEN, H C KLEIN AND THE DANISH OBESITY PROJECT*
}

From the Department of Medicine, Division of Hepatology, Hvidovre University Hospital, Copenhagen, Denmark, Departments of Surgical Gastroenterology, Department of Radiology, Herlev University Hospital, Copenhagen, Denmark, and Departments of Medical Gastroenterology, Department of Radiology, Rigshospitalet, University of Copenhagen, Denmark

SUMmARY The relationship between cholesterol in plasma and risk of gall stone formation was investigated in 210 obese patients who underwent jejunoileal bypass surgery and were free of gall stone disease at that time. Among 185, successfully reexamined on average 19 months after surgery, $26(14 \%)$ developed gall stones. The fall in plasma cholesterol after surgery exhibited a U-shaped relation to risk of gall stone formation with a minimum risk around the average fall $(2.6 \mathrm{mmol} / \mathrm{l})$. This was confirmed by multivariate logistic regression analysis $(\mathrm{p}<0.01)$ taking into account other possible determinants. The relation was not significantly dependent on weight loss or ratio between jejunum and ileum left in function. The study suggests that malabsorption induced fall in plasma cholesterol is related to risk of gall stone formation by two oppositely working mechanisms, one enhancing and one reducing the risk.

The relationship between plasma cholesterol ( $p$ cholesterol) and cholesterol gall stone formation, already focussed upon in the beginning of the century,' has been extensively studied, ${ }^{2-x}$ but is unclarified, and it appears that no biologically simple relationship exists. The regulation of hepatic secretion of cholesterol to plasma and bile is still poorly understood, but both hepatic uptake and production of cholesterol is subject to feed back regulation dependent on hepatic requirement for cholesterol. ${ }^{.12}$ This suggests that a relation between p-cholesterol and biliary lithogenicity may appear only when the homeostatic mechanisms are either altered or exhausted. Previous studies have not assessed the relationship between the individual changes in pcholesterol and the subsequent risk of gall stone formation. Moreover, p-cholesterol has been examined cross sectionally in relation to the presence

\footnotetext{
Address for correspondence: Dr T I A Sorensen. Dept of Medicine 233. Division of Hepatology, Hvidovre University Hospital, DK 2650 Copenhagen, Denmark.

Received for publication 17 June 1987

*Members of the Danish Obesity Project are: O G Backer. E Gudmand-Høyer. B Andersen, H Baden, P J Martiny, E Juhl, F Quaade, K H Stockholm B Halver, O Noring, O Iversen, S Madsen, K Gotlieb-Jensen, P Danø, L Storgaard. O V Nielsen. A Marckmann. U Starup. K Emmertsen. $K$ E Petersen. D Andersen. N Schwartz-Sorensen, and L Mosekilde.
}

of gall stones or, if prospectively, then only in relation to manifestations rather than to formation of gall stones.

Short bowel syndrome, as induced by jejunoileal bypass surgery for obesity, results in a marked fall in p-cholesterol, ${ }^{13}$ particularly in the low density lipoprotein (LDL) fraction, ${ }^{1+}$ and an increased risk of gall stone formation. ${ }^{15}$ In the present prospective study we investigated the change in p-cholesterol after jejunoileal bypass surgery in relation to the subsequent incidence of gall stone formation and took into account other factors of possible influence on the risk of gall stone formation. Although jejunoileal bypass surgery for obesity represents a specific, extreme condition, these patients are particularly suitable for investigation of this relationship because of (i) the high incidence of postoperative gall stone formation ${ }^{15}$ which makes prospective studies practicable, (ii) the well defined intervention on an otherwise normal intestine, (iii) the feasibility of prospective ascertainment of potential determinants among patients free of gall stones at time of surgery, (iv) the distinct, immediate fall in p-cholesterol which exhibits a considerable interindividual variation and is poorly correlated with the faecal bile salt loss, ${ }^{1316}$ and, finally, (v) the possibility of assessing the relationship 
at different degrees of cholesterol and bile acid malabsorption according to differences in ratio between jejunum and ileum left in continuity. ${ }^{17}$

\section{Methods}

PATIENT POPULATION

Ten hospitals, participating in The Danish Obesity Project, ${ }^{18}$ made available for the study 375 morbidly obese patients considered for bypass surgery either as part of, or before or after, the project. Among them 76 were not operated on, and the remaining 299 patients had an end-to-side jejunoileal bypass according to a standardised surgical procedure. ${ }^{18}$ The length of jejunum and ileum left in continuity alternated between 3:1 $(n=163)$ and 1:3 $(n=136)$. The patients gave informed consent to the examination procedures.

\section{ASCERTAINMENT OF GALL STONES}

Patients not cholecystectomised were examined before and after bypass surgery with oral cholecystography and/or intravenous cholangiography. When an $x$-ray examination was considered technically insufficient a further one was carried out. The preoperative examination was carried out within a few months before surgery. The postoperative examination was planned as a single cross sectional survey of eligible patients and was carried out mean 18.9 months ( $\mathrm{SD}=12.5$ months) after surgery. Patients without stones at time of surgery who had presented symptomatic gall stone disease before the planned postoperative examination were assigned for the analyses a follow up period corresponding to this examination. All radiographs were evaluated twice, independently and with a time interval of approximately two weeks, by each of two experienced radiologists (LIJ and OP, or LIJ and KL) who had no knowledge about the individual patients. The four readings showed a very high intra and interobserver reliability, ${ }^{14}$ but when there was disagreement, the diagnoses were made on the basis of majority rules. ${ }^{15}$ The radiological criteria for the presence of gall stones were either filling defects in the cholecystograms or positive stone shadows at the position of the gall bladder on plain films. Nonvisualisation of the gall bladder was considered insufficient for diagnosis in this study. In order to classify the gall stones as to whether they were of cholesterol type or not, form, number, size and radiolucency were recorded. ${ }^{20}$

\section{MEASUREMENTS}

Before surgery, height, body weight and pcholesterol were measured. After surgery, most patients were seen monthly the first half year and at increasing intervals thereafter for weighing and blood sampling. The p-cholesterol was routinely determined by the Liebermann-Burchard method modified for autoanalyser. ${ }^{21}$ In the statistical analyses, the values of weight loss and fall in pcholesterol were used at the time when both had obtained stable concentrations, that is at one year after surgery. ${ }^{13}$ These values are expected to correlate highly with preceding postoperative levels. It is conceivable, however, that differences in $p$ cholesterol at one year after surgery could be caused by gall bladder dysfunction in consequence of gall stone formation. On the other hand, p-cholesterol could be related to gall stone formation only during the early postoperative period and not at one year after surgery. Therefore, the p-cholesterol concentrations during the first postoperative year in patients forming stones were compared with those of control patients, not forming stones (selection of matched control patients are described later).

DELINEATION OF THE SAMPLE (Fig. 1)

Among the 299 bypass patients made available for the study, 23 had previously been cholecystectomised. The preoperative $x$-ray examination was not done in 14 patients, and was insufficient for diagnosis because of no or faint visualisation of the gall bladder, frequently because of presence of gall stones as subsequently shown during surgery, in 30 patients. Among the 232 patients successfully examined before surgery, 22 had gall stones. Thus, 210 patients were eligible for postoperative follow up examination, which was carried out in 201 patients: by oral cholecystography in 129 , intravenous cholangiography in 59, biliary surgery in nine, intraoperative palpation in two, autopsy in one, and clinical diagnosis in one (with jaundice, signs of cholecystitis and non-visualisation of the gall bladder by cholangiography). Nine patients were not re-examined because of refusal, emigration, pregnancy, and sensitivity to contrast medium: Despite several attempts,

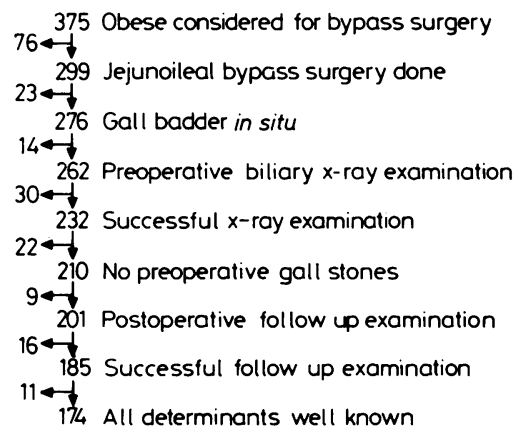

Fig. 1 Delineation of the study sample. 
the follow up examination was technically insufficient in 16 patients leaving 185 for the analyses. Complete information regarding all variables used in the analyses was available in 174 patients.

STATISTICAL ANALYSES

The relation between presence of gall stones and pcholesterol was analysed by the Mann-Whitney test and the multivariate logistic regression procedure..$^{22} 23$ By the multivariate procedure the comparability regarding the possibly confounding covariables is improved when assessing the effects of p-cholesterol. The time from surgery to examination for gall stones has been taken into account as a covariable because the likelihood of finding gall stones may increase with time because of stone formation, stone growth, as well as improved conditions for examination (failure time models are inapplicable because time to stone formation is unknown). Other covariables were sex, age, height, preoperative weight, shunt length, jejunoileal ratio of the shunt, weight loss at one year after surgery, and whether or not the patient was included in the Danish Obesity Project (recruitment route). In order to optimise the control of their confounding effects all covariables have been included in the model independent of their statistical significance. For the analysis of the postoperative course all patients forming gall stones, irrespective of time of detection of the stones, were compared with pair wise matched controls, who were selected as bypass patients not developing gall stones, but whose a priori risk of gall stone formation, estimated from the regression model by keeping postoperative weight loss and fall in p-cholesterol constant, was

Table 1 Characteristics of the patients with and without gall stone formation after jejunoileal bypass surgery

\begin{tabular}{lll}
\hline & \multicolumn{1}{l}{$\begin{array}{l}\text { Postoperative gall stone } \\
\text { formation }\end{array}$} \\
\cline { 2 - 3 } & $\begin{array}{l}\text { Yes } \\
(n=26)\end{array}$ & $\begin{array}{l}\text { No } \\
(n=159)\end{array}$ \\
Characteristics & & \\
\hline Preoperative & 81 & 75 \\
Females $(\%)$ & $33 \pm 7$ & $32 \pm 9$ \\
Age (years) & $166 \pm 9$ & $168 \pm 8$ \\
Height (cm) & $128 \pm 18$ & $128 \pm 18$ \\
Weight (kg) & $6 \cdot 16 \pm 1 \cdot 37$ & $6 \cdot 12 \pm 1 \cdot 14 *$ \\
P-cholesterol (mmol/l) & 77 & 72 \\
Surgical & 77 & 70 \\
Shunt length 50 cm (\%) & 65 & 43 \\
Recruitment from DOP $(\%)$ & & $39 \cdot 4 \pm 14 \cdot 2$ \\
Jejunoileal ratio 1:3(\%) & $42 \cdot 7 \pm 16 \cdot 5$ & $2 \cdot 60 \pm 1 \cdot 11+$ \\
Postoperative & $2 \cdot 58 \pm 1 \cdot 50$ & \\
Weight loss (kg) & & \\
P-cholesterol fall (mmol/l) & & \\
\hline
\end{tabular}

${ }^{*}$ Missing values in nine; $†$ Missing values in six. most similar to the risk estimates of those who actually developed stones.

\section{Results}

Among the 185 patients without gall stone disease preoperatively, and a successful follow up examination, gallstones were found in 26 patients $(14 \%)$. In all but three patients the gall stones were radiolucent (two showed a laminar opacity and one a faint, diffuse opacity). The stones were visualised in 22 patients and appeared round in 20. Median number of stones was six (range 1-30) and median size was $4 \mathrm{~mm}$ for the smallest and $7 \mathrm{~mm}$ for the largest in each case (range 2-25 mm). Complete information about the variables of interests was available in all patients developing gall stones, whereas in few patients not developing stones pre- and postoperative pcholesterol were unknown (Table 1).

The mean values of the preoperative p-cholesterol and the postoperative fall showed no differences between those who developed gall stones, and those who did not (Table 1). Correspondingly, the MannWhitney test revealed no significant difference, but this way of looking at the data does not take into account the greater variation in p-cholesterol among those who formed stones. Such finding indicates a $\mathrm{U}$-shaped relation between $\mathrm{p}$-cholesterol and the risk of gall stone formation (Fig. 2), which may be further examined in the logistic regression model (see below). The 16 patients, who were unsuccessfully examined for gall stones and the nine patients, who escaped this examination, were fairly similar to those successfully examined (data not shown).

The necessity of carrying out a multivariate analysis follows from the findings that fall in $p$ cholesterol was significantly related to the preoperative level $(p<0 \cdot 001)$, the jejunoileal ratio of the shunt

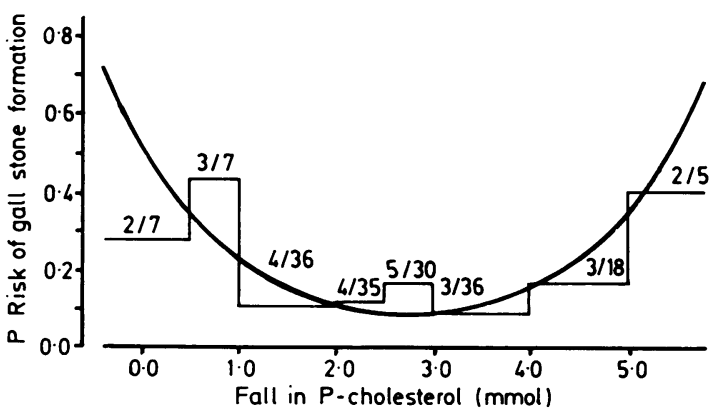

Fig. 2 Risk of gall stone formation after jejunoileal bypass surgery in relation to fall in p-cholesterol. Thin lines and the numbers above them represent the crude frequencies within intervals of fall in p-cholesterol and the thick line shows the risk function derived from multivariate logistic regression analysis. 
Table 2 Logistic regression model for risk of gall stone formation after jejunoileal bypass surgery based on 174 patients

\begin{tabular}{|c|c|c|c|}
\hline $\begin{array}{l}\text { Characteristics } \\
\text { (units or classes*) }\end{array}$ & Coefficient ${ }^{\dagger}$ & $S E$ & $P$ \\
\hline \multicolumn{4}{|l|}{ Preoperative } \\
\hline Sex (female/male) & 0.414 & $0 \cdot 801$ & $0 \cdot 6$ \\
\hline Age (years) & $0 \cdot 021$ & 0.028 & $0 \cdot 5$ \\
\hline Height $(\mathrm{cm})$ & -0.024 & 0.045 & $0 \cdot 6$ \\
\hline Weight (kg) & $-0 \cdot 019$ & 0.022 & $0 \cdot 4$ \\
\hline P-cholesterol (mmol/l) & $-0 \cdot 001$ & 0.004 & $0 \cdot 9$ \\
\hline \multicolumn{4}{|l|}{ Surgical } \\
\hline Shunt length $(50 / 47 \cdot 5 \mathrm{~cm})$ & 0.699 & $0 \cdot 722$ & $0 \cdot 4$ \\
\hline Recruitment DOP (yes/no) & $-0 \cdot 282$ & $0 \cdot 678$ & $0 \cdot 7$ \\
\hline Jejunoileal ratio $(1: 3 / 3: 1)$ & $1 \cdot 143$ & 0.499 & 0.022 \\
\hline \multicolumn{4}{|l|}{ Postoperative } \\
\hline Duration of follow up (years) & $0 \cdot 241$ & $0 \cdot 270$ & 0.4 \\
\hline Weight loss (kg) & 0.053 & 0.025 & 0.033 \\
\hline P-cholesterol fall $(\mathrm{mmol} / \mathrm{l})$ & $-1 \cdot 698$ & 0.666 & $0 \cdot 011$ \\
\hline Do squared & $0 \cdot 317$ & $0 \cdot 120$ & 0.009 \\
\hline
\end{tabular}

${ }^{*}$ Coefficients refer to the first mentioned class; †Odds ratios may be derived by exp (coefficient).

$(\mathrm{p}<0 \cdot 05)$ and the loss of weight $(\mathrm{p}<0 \cdot 05)$. Table 2 shows the logistic regression model based on the 174 patients in whom postoperative examination for gall stones was successful and all characteristics were known. A model including those unsuccessfully examined as if they had formed stones and those who escaped follow up examination as if they had not, showed essentially the same statistically significant, relationships. Sex, age, height, preoperative weight, shunt length, recruitment route, and duration of the follow-up period had no significant, independent effect on the risk of gall stone formation. The risk was significantly higher with a 1:3 than with a 3:1 jejunoileal ratio of the shunt (as previously found ${ }^{15}$ ), and the risk increased significantly with increasing weight loss.

Preoperative p-cholesterol still had no significant influence on risk of gall stone formation, but the analysis confirmed that there was a highly significant $\mathrm{U}$-shaped relationship between fall in p-cholesterol and the risk. Translating the estimated coefficients to odds ratios, this means that, in comparison to the risk at a fall of $2.6 \mathrm{mmol} / \mathrm{l}$ (mean value), a fall in $\mathrm{p}$ cholesterol that is $2 \mathrm{mmol} / \mathrm{l}$ either lower or higher increases the odds by 3.9 and 3.2 , respectively. The risk function over the entire range of fall in pcholesterol is shown in Figure 2 together with the frequencies of gall stones on the basis of the crude results. The effect of fall in p-cholesterol was not significantly dependent on the jejunoileal ratio or the degree of weight loss (no significant interaction terms).

For comparison with the 26 gall stone patients

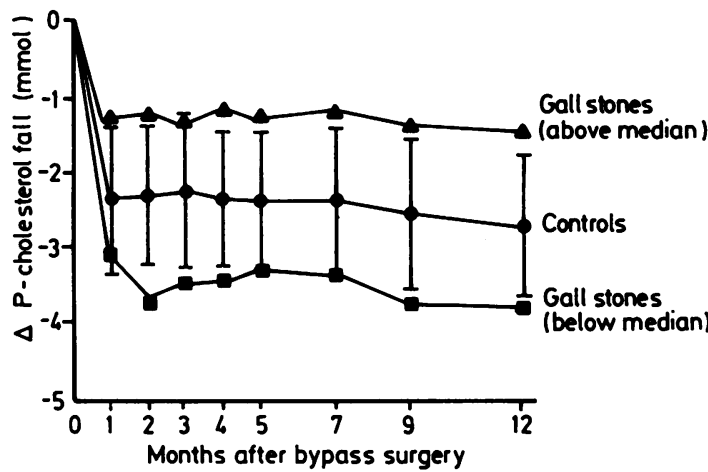

Fig. 3 Course of fall in plasma cholesterol after jejunoileal bypass surgery in patients developing gall stones after surgery and in pair wise matched controls of similar a priori risk of gall stone formation according to the logistic regression model (see text). The gall stone group has been divided in two groups according to fall in p-cholesterol at one year follow up. Values are means with indication of one $S D$ for the control group.

regarding the p-cholesterol concentrations during the first postoperative year, we selected 26 patients among the 159 patients who showed no stones at postoperative examination and on whom complete information was available. According to the logistic regression model including preoperative and surgical characteristics and duration of follow up periods, those selected had the same risk of gall stone formation as the gall stone patients. Figure 3 shows that the gall stone patients, whether having a fall in pcholesterol above or below the median value at one year, had a similar first year course as those not developing stones.

\section{Discussion}

The fall in p-cholesterol after jejunoileal bypass proved to have a U-shaped relation to risk of gall stone formation. This observation has been possible because of the prospective study of a rather large series of patients representing a broad range of fall of p-cholesterol and of the prospective approach in the data analyses. The validity of the finding is primarily dependent on unbiased follow up examination, but there seems to be no reason to suspect errors that could produce such results. The relationship stands up to the multivariate analysis which controls for several other factors of known or possible influence on the risk of gall stone formation. The characteristics of the gall stones make it reasonable to interpret the finding in terms of cholesterol gall stone pathogenesis. ${ }^{20}$

The risk function for gall stone formation (Fig. 2) 
may be considered as a combination of two different functions, one decreasing and the other increasing by increasing fall in p-cholesterol. The interpretation of these risk functions may be difficult because of the great and variable loss of weight which, in itelf, has a profound influence on cholesterol metabolism, ${ }^{24}$ and the severe malabsorption of cholesterol and bile acids caused by the short jejunum and ileum, respectively, left in function. ${ }^{1617}$ It is, therefore, of particular importance that although weight loss and jejunoileal ratio of the bypass correlated significantly with the fall in p-cholesterol, neither showed a significant interaction with the relation between fall in $p$ cholesterol and risk of gall stone formation.

The fall in total p-cholesterol is accounted for mainly by a fall in LDL cholesterol. ${ }^{101+}$ This fall seems to be the result of an increased hepatic uptake of LDL cholesterol mediated by stimulation of specific lipoprotein receptors (apolipoprotein B, E receptors) according to the increased hepatic requirement for bile acid synthesis. ${ }^{y-11}$ Under these circumstances a major part of cholesterol for both bile acid synthesis and biliary cholesterol secretion is derived from cholesterol in plasma rather than from newly synthesised cholesterol. ${ }^{25}$ Biliary cholesterol secretion is largely independent of biliary bile acid secretion..$^{12}$ We suggest some putative explanation of our findings on the basis of the assumptions that either the hepatic uptake or synthesis of cholesterol are poorly accommodated to the hepatic requirement for bile acid synthesis.

Thus, the right, increasing part of the risk function could reflect excessive hepatic uptake of cholesterol which may result in increased biliary secretion of cholesterol relative to bile acids and, hence, increased lithogenicity. The left, decreasing part of the risk function, on the other hand, then may correspond to increasing supply of cholesterol for bile acid synthesis resulting in increased biliary secretion of bile acids relative to cholesterol and decreasing lithogenicity. In another argument, assuming poor accommodation of hepatic cholesterol synthesis, the increased lithogenicity and small reduction in p-cholesterol at the left part of the risk function may be because of excessive cholesterol production resulting in both reduced hepatic uptake and increased biliary secretion of cholesterol. At the opposite end of the risk function, the cholesterol production may be too low, so, although the hepatic uptake of cholesterol, and hence the reduction in p-cholesterol, is large, the synthesis and subsequently the secretion of bile acids is reduced relative to the obligatory biliary secretion of cholesterol.

The observation of two oppositely acting risk functions, disentangled during the extreme conditions of combined cholesterol and bile acid malabsorption after jejunoileal bypass surgery, has revealed some specific limitations of the homeostatic mechanisms of hepatic cholesterol metabolism. This raises the question to what extent these mechanisms are operating under other conditions, which may make the observations pertinent to understanding of cholesterol gall stone pathogenesis.

The paper has been presented at the 19th Scandinavian Conference on Gastroenterology; abstract no 129. Scand J Gastroenterol 1986; 21: suppl 120: 78. This study was supported by the Danish Medical Research council (grants nos 512-8218, 512-8958, 124448). We thank Søren Spelling, cand stat, for carrying out data management and statistical analyses. Merete von Holstein and Inger-Lise Petersen are acknowledged for secretarial assistance.

\section{References}

1 Aschoff L, Bachmeister A. Die Cholelithiasis. Jena: Fisher, 1909.

2 Friedman GD, Kannel WB, Dawber TR. The epidemiology of gallbladder disease: observations in the Framingham study. J Chronic Dis 1966; 19: 273-92.

3 Sturdevant RAL, Pearce ML, Dayton S. Increased prevalence of cholelithiasis in men ingesting a serumcholesterol-lowering diet. N Engl J Med 1973; 288: 24-7.

4 The Coronary Drug Project Research Group. Gallbladder disease as a side effect of drugs influencing lipid metabolism: experience in the Coronary Drug Project. N Engl J Med 1977; 296: 1185-90.

5 Linden Wvd, Bergman F. An analysis of data on human bile: relationship between main bile components, serum cholesterol and serum triglycerides. Scand J Clin Lab Invest 1977; 37: 741-7.

6 Ahlberg J, Angelin B, Einarsson K, Hellstrom K, Leijd B. Biliary lipid composition in normo- and hyperlipoproteinemia. Gastroenterology 1980; 79: 90-4.

7 Thornton JR, Heaton KW, MacFarlane DG. A relation between high-density-lipoprotein cholesterol and bile cholesterol saturation. Br Med J 1981; 283: 1352-4.

8 Scragg RKR, Calvert CD, Oliver JR. Plasma lipids and insulin in gall stone disease: a case-control study. $\mathrm{Br}$ Med J 1984; 289: 521-5.

9 Goldstein JL, Brown MS. Progress in understanding the LDL receptor and $\mathrm{HMG}-\mathrm{CoA}$ reductase, two membrane proteins that regulate the plasma cholesterol. J Lipid Res 1984; 25: 1450-61.

10 Packart CJ, Shepherd J. The hepatobiliary axis and lipoprotein metabolism: effects of bile acid sequestrants and ileal bypass surgery. $J$ Lipd Res 1982; 23: 1081-8.

11 Mahley RW, Innerarity TL. Lipoprotein receptors and cholesterol homeostasis. Biochim Biophys Acta 1983; 737: 197-222.

12 Carey MC, Mazer NA. Biliary lipid secretion in health and in cholesterol gallstone disease. Hepatology 1984; 4: suppl: 31-7. 
13 Sørensen TIA, Andersen B, Kam-Hansen L, The Danish Obesity Project. Total plasma cholesterol in obesity after jejunoileal bypass with $3: 1$ or $1: 3$ jejunoileal ratio. Scand J Gastroenterol 1979; 14: 865-8.

14 Sørensen TIA, Andersen B, Damgaard-Pedersen F. Plasma cholesterol fractions after jejunoileal bypass with $3: 1$ or $1: 3$ jejunoileal ratio. Scand J Gastroenterol 1982; 17: 199-203.

15 Sørensen TIA, Jensen LI, Klein HC, et al. The Danish Obesity Project. Risk of gallstone formation after jejunoileal bypass increases more with a $1: 3$ than with a 3:1 jejunoileal ratio. Scand J Gastroenterol 1980; 15: 979-84.

16 Faloon WW, Rubulis A, Knipp J, Sherman CD, Flood MS. Fecal fat, bile acid, and sterol excretion and biliary lipid changes in jejunoileostomy patients. Am J Clin Nutr 1977; 30: 21-31.

17 Sørensen TIA, Hylander E, Miettinen TA. Faecal steroids after jejunoileal bypass with $3: 1$ or $1: 3$ jejunoileal ratio. Scand J Gastroenterol 1985; 20: 205-8.

18 The Danish Obesity Project. Randomised trial of jejunoileal bypass versus medical treatment in morbid obesity. Lancet 1979 ; ii: $1255-8$.
19 Jensen LI, Sørensen TIA, Laursen K, Klein HC, Petersen O. Reliability of evaluation of gallbladder X-ray examinations. Dan Med Bull 1982; 29: 305-8.

20) Dolgin SM, Schwartz JS, Kressel HY, et al. Identification of patients with cholesterol or pigment gallstones by discriminant analysis of radiographic features. $N$ Engl $J$ Med 1981; 304: 808-11.

21 Huang TC, Chen CP, Wefler V, Raftery A. A stable reagent for the Liebermann-Burchard reaction: application to rapid serum cholesterol determination. Anal Chem 1961; 33: 1405-7.

22 Walker SH, Duncan DB. Estimation of the probability of an event as a function of several independent variables. Biometrika 1967; 54: 167-79.

23 SAS supplemental user's guide. Cary, North Carolina: SAS Institute, 1983.

24 Bennion LJ, Grundy SM. Effects of obesity and caloric intake on biliary lipid metabolism in man. J Clin Invest 1975; 56: 996-1011.

25 Schwartz CC, Berman M, Vlahcevic ZR, Halloran LG, Gregory DH, Swell L. Multicompartmental analysis of cholesterol metabolism in man: characterization of the hepatic bile acid and biliary cholesterol precursor sites. J Clin Invest 1978; 61: 408-23. 